\title{
Impact of Chess Training on Academic Performance of Rural Indian School Children
}

\author{
Ebenezer Joseph $^{1}$, Veena Easvaradoss ${ }^{2}$, N. Josiah Solomon ${ }^{3}$ \\ ${ }^{1}$ Government of India, Part-Time Research Scholar, Madras University, Chennai, India \\ ${ }^{2}$ Department of Psychology, Women's Christian College, Chennai, India \\ ${ }^{3}$ Department of Statistics, Madras Christian College, Chennai, India \\ Email: emmanuelchess@gmail.com
}

Received 19 January 2016; accepted 16 February 2016; published 23 February 2016

\begin{abstract}
The objective of this study was to examine the effect of chess training on academic performance of middle school children in rural India. The impact of chess on various academic courses was examined. The sample consisted of 100 students of sixth grade with an intervention group undergoing chess training and a control group. Statistical tests were carried out to examine whether the performance of students has improved after chess intervention. The results of the paired samples t-test analysis showed significant improvement in academic performances of students in English, social studies and science, after a year of training in chess skills. The study has important implications for education.
\end{abstract}

\section{Keywords}

Chess Training, Cognitive Development, Academic Performance, School Children

\section{Introduction}

Chess is a classic game of strategy, invented more than 1500 years ago in India. Legend has it that the ruler of India asked his wise men to devise a way to teach the children of the royal family to become better thinkers and better generals on the battlefield. Chess was the result. In the centuries since its invention, chess has spread to every country in the world. Chess has long been considered a way for children to increase their mental prowess, concentration, memory, and analytical skills.

Improved memory is just the tip of the iceberg. Reports from students, teachers, and parents noticed the academic benefits of chess on math problem solving skills and reading comprehension, an increase in self-confidence, patience, logic, critical thinking, observation, pattern recognition, analysis, creativity, concentration, persistence, self-control, sportsmanship, responsibility, respect for others, self-esteem, coping with frustration, and many other influences which are difficult to measure but can make a difference in student attitude, motivation, and achievement.

The beauty of chess as a teaching tool is that it stimulates children's minds and helps them to build these skills 
while enjoying themselves. As a result, children become more critical thinkers, better problem solvers, and more independent decision makers.

In the schools, chess often serves as a bridge, bringing together children of different ages, races and genders in an activity they can all enjoy. Chess helps build individual friendships and also school spirit when children compete together as teams against other schools. Chess also teaches children about sportsmanship how to win graciously and not give up when encountering defeat. For children with adjustment issues, there are many examples where chess has led to increased motivation, improved behaviour, better self-image, and even improved attendance. Chess provides a positive social outlet, a wholesome recreational activity that can be easily learned and enjoyed at any age.

Chess has shown to improve the academic performance of children. The increase in academic performance points to the fact that the children have been able to understand concepts better and have acquired better memory and problem-solving skills. Equipping the younger generation with these skills makes them empowered citizens of the future, who might have far-reaching impact on the society at large.

Many schools all over the world encourage chess play to enhance academic performance. Studying chess systematically has also shown to raise students' IQ and exam scores (Dullea 1982; Palm 1990; Ferguson 2000) [1]-[3], as well as strengthen mathematical, language, and reading skills (Margulies 1992; Liptrap 1998; Ferguson 2000) [3]-[5].

In Marina, California, an experiment with chess indicated that after only 20 days of instruction, students' academic performance improved dramatically. George L. Stephenson, chairman of the Marina JHS math department, reported that $55 \%$ of the students showed significant improvement in academic performance after this brief smattering of chess instruction. Douglas Williams (2014) [6] and Hong and Bart (2007) [7] examined the cognitive effects of chess instruction on students at risk of academic failure in Korea. They reported that chess instruction produces higher chess skill ratings. This may lead to gains in levels of non-verbal intelligence among students at risk of academic failure.

Although chess originated in India, research assessing its impact on the academic performance and cognitive development of children is not available. The primary objective of this research is to evaluate and measure the enhancement of academic performance with chess. This is an essential step towards proving the benefits of chess for an Indian population. Such research can also help to seriously consider the use of chess within educational curriculums and schools in India.

Keeping this objective in mind, the following research questions were posed: Does chess intervention cause an increase in the academic performance of children in low socioeconomic backgrounds? Is there a significant difference in the academic performance of children after a chess intervention of one year (approximately 30 sessions a year)? Has chess intervention caused an increase in performance in specific subjects like English, mathematics, science and social studies (assuming the other intervening variables to be constant)? How has chess caused the following increases?

\section{Research Design}

The study used the experimental method research design. This study used a pre-test and post-test design with a control group. The experimental group chosen purposively and a random control group. The independent variable in the study was the chess intervention and the dependent variables were academic scores in English, mathematics, science, social studies and Tamil (a local language). Chess training was given once a week for a duration of one year.

\section{Sample}

The participants of the study were 100 sixth grade students studying in a semirural area in South Tamil Nadu, India. The school caters primarily to children from the lower socio-economic status, with most of the parents having only school education.

\section{Measures}

The students were assessed by their academic performance in English, mathematics, science, social studies and Tamil before and after chess intervention for a period of one year. 


\section{Procedure}

Students' academic marks were collected from school. Their academic marks were again collected after chess intervention of one year. Chess training consisted of standardized once in a week training sessions of one hour duration over a period of one year. Clustering technique was used to form the training groups. Chess training was done using the following methodology.

- DVD learning (Winning Moves, Episodes 1 - 22)

- Demonstration board

- On-the-board training

- Chess exercise through workbooks (Chess school 1A, Chess school 2, and tactics)

- Chess playing on computer (Kasparov’s Chessmate, Fritz)

- Tactical chess training using software (Maurice Ashley Teaches Chess, Advance Chess School, CT ART 3.0)

- Mapping the prodigies games using chess base software and understating brain patterns of the child

- Cognitive correction using softwares for problems such as perception for normal as well as special children

- End game training using Theory and practice of End Games, ABC of Endgames and Winning Moves DVD

- Ideas behind chess openings

- Exposure to classical games

- Chess playing sessions

- Mock training tournaments

- Participation in regular chess tournaments

- Analysis of score sheets and thought patterns

From the Table 1 and Table 2, in the experimental group, we observe that there is no significant difference in the Tamil average marks and there is significant difference in the English, maths, science and social studies in sixth and seventh standard marks.

Table 1. Paired samples $t$-test of experimental group.

\begin{tabular}{|c|c|c|c|c|c|c|}
\hline & & Mean & $\mathrm{N}$ & Standard. Deviation & Standard Error Mean & $t$ \\
\hline \multirow{2}{*}{ Pair 1} & 6th Std. Tamil average mark & 52.00 & 48 & 15.684 & 2.264 & \multirow{2}{*}{-1.041} \\
\hline & 7th Std. Tamil average mark & 53.60 & 48 & 15.994 & 2.309 & \\
\hline \multirow{2}{*}{ Pair 2} & 6th Std. English average mark & 55.10 & 48 & 14.565 & 2.102 & \multirow{2}{*}{$-2.072^{*}$} \\
\hline & 7th Std. English average mark & 57.38 & 48 & 14.013 & 2.023 & \\
\hline \multirow{2}{*}{ Pair 3} & 6th Std. Maths average mark & 61.06 & 48 & 18.778 & 2.710 & \multirow{2}{*}{$2.679^{* *}$} \\
\hline & 7th Std. Maths average mark & 56.38 & 48 & 16.086 & 2.322 & \\
\hline \multirow{2}{*}{ Pair 4} & 6th Std. Science average mark & 53.81 & 48 & 18.571 & 2.680 & \multirow{2}{*}{$-2.804^{* *}$} \\
\hline & 7th Std. Science average mark & 57.71 & 48 & 15.545 & 2.244 & \\
\hline \multirow{2}{*}{ Pair 5} & 6th Std. Social average mark & 63.25 & 48 & 19.165 & 2.766 & \multirow{2}{*}{$4.585^{* *}$} \\
\hline & 7th Std. Social average mark & 55.15 & 48 & 16.151 & 2.331 & \\
\hline
\end{tabular}

${ }^{*} p<0.05,{ }^{* *} p<0.01$.

Table 2. Paired samples $t$-test of control group paired samples statistics.

\begin{tabular}{|c|c|c|c|c|c|c|}
\hline & & Mean & $\mathrm{N}$ & Standard. Deviation & Standard Error Mean & $t$ \\
\hline \multirow{2}{*}{ Pair 1} & 6th Std. Tamil average mark & 55.36 & 52 & 17.147 & 2.378 & \multirow{2}{*}{-1.783} \\
\hline & 7th Std. Tamil average mark & 57.60 & 52 & 16.722 & 2.319 & \\
\hline \multirow{2}{*}{ Pair 2} & 6th Std. English average mark & 59.43 & 52 & 15.833 & 2.196 & \multirow{2}{*}{-0.926} \\
\hline & 7th Std. English average mark & 60.47 & 52 & 13.604 & 1.886 & \\
\hline \multirow{2}{*}{ Pair 3} & 6th Std. Maths average mark & 62.18 & 52 & 18.575 & 2.576 & \multirow{2}{*}{$3.467^{* *}$} \\
\hline & 7th Std. Maths average mark & 57.09 & 52 & 16.933 & 2.348 & \\
\hline \multirow{2}{*}{ Pair 4} & 6th Std. Science average mark & 55.72 & 52 & 19.455 & 2.698 & \multirow{2}{*}{$-2.537^{* *}$} \\
\hline & 7th Std. Science average mark & 59.99 & 52 & 15.665 & 2.172 & \\
\hline \multirow{2}{*}{ Pair 5} & 6th Std. Social average mark & 67.45 & 52 & 19.394 & 2.689 & \multirow{2}{*}{$4.726^{* *}$} \\
\hline & 7th Std. Social average mark & 58.60 & 52 & 16.414 & 2.276 & \\
\hline
\end{tabular}

${ }^{*} p<0.05,{ }^{* *} p<0.01$. 


\section{Results}

The results were analyzed using SPSS 20. There was a significant increase in the experimental group in all the subjects except Tamil. Even though, the control group showed increase in academic performance in some of the subjects, the gains of the experimental group were higher than those of the control group, and the earlier deficiency in the academic performance was removed after chess intervention.

\section{Discussion}

It is interesting to note that the academic performance in almost all the courses (excluding Tamil) showed an increase following chess training in this study. This is not totally unexpected as we observe that chess playing focuses on developing cognitive skills like focusing, visualizing, thinking ahead, weighing options, analyzing concretely, thinking abstractly, planning, and juggling multiple considerations simultaneously, which would invariably have its effect on the academic performance of the students. Over time, chess helps develop patience and thoughtfulness.

It was noticed in the study that the academic performance of the children $(\mathrm{N}=48)$ who chose to play chess was lower than that of the randomly chosen control group, prior to the intervention. It was also noticed in another study conducted by the Emmanuel Chess Centre that the IQ scores of the children who chose to play chess were higher than those of the randomly selected control group, that is the children who opt to play chess have higher IQ but lower academic performance prior to the chess intervention. In this study, the impact of chess training was analyzed to study whether the difference in the academic performance was bridged.

Trinchero (2013) [8] reported similar findings in 556 primary school children who were undergoing chess training. One prominent result was that the experimental group that received chess training registered a modest but statistically significant increase in scores on mathematics test items that required problem-solving skills on complex tasks. This effect was greater among students who had more hours of chess instruction.

Scholz et al. (2008) [9] investigated the effects of chess training on mathematics learning among students with learning disabilities, based on intelligence scores in the 70 - 85 IQ range. Classes from four elementary schools in Germany were randomly assigned to two groups: (a) an experimental group that received chess instruction of one hour per week for one entire school year and (b) a comparison group that received supplementary mathematics instruction for one hour per week. The two groups did differ significantly, in their calculation abilities for simple addition tasks and counting.

Smith and Cage (2000) [10] reported the effects of 120 hours of chess instruction on the mathematics achievement among rural, African-American secondary school students. They determined that the treatment group scored significantly higher in mathematics achievement and non-verbal cognitive ability than the control group after controlling for differences among pretest scores.

\section{Implications}

Chess is a game that can be used to develop cognitive skills in children. The simplicity of the game makes it a versatile tool that can be used in schools, homes, and intervention centres. Children learn to play together and win and lose; they learn valuable lessons that will generalize to academic functioning. It is evident from the study that chess impacts cognitive development in children and there is a significant improvement in the academic performance of the children who underwent chess training.

\section{References}

[1] Dullea, G.J. (1982) Chess Makes Kids Smarter. Chess Life, 1.

[2] Palm, C. (1990) Chess Improves Academic Performance. New York City Schools Chess Program, 12.

[3] Ferguson, R. (2000) The Use and Impact of CHESS. Section B, USA Junior Chess Olympics Curriculum. 53.

[4] Margulies, S. (1992) The Effect of Chess on Reading Scores: District Nine Chess Program, Second Year Report. The American Chess Foundation, New York.

[5] Liptrap, J.M. (1998) Chess and Standard Test Scores. Chess Life, 41-43.

[6] Williams, D. (2014) The Game of Chess: A Conduit to Increase Student Academic Achievement in Pinclas County; a Policy Advocacy Document. 3.

[7] Hong, S. and Bart, W.M. (2007) Cognitive Effects of Chess Instruction on Students at Risk for Academic Failure. In- 
ternational Journal of Special Education, 22, 89-96.

[8] Trinchero, R. (2013) Can Chess Training Improve Pisa Scores in Mathematics? An Experiment in Italian Primary Schools. Kasparov Chess Foundation, Europe.

[9] Scholz, M., Niesch, H., Steffen, O., Ernst, B., Loeffler, M., Witruk, E. and Schwarz, H. (2008) Impact of Chess Training on Mathematical Performance and Concentration Ability of Children with Learning Disabilities. International Journal of Special Education, 23, 138-148.

[10] Smith, J.P. and Cage, B.N. (2000) The Effects of Chess Instruction on the Mathematics Achievements of Southern, Rural, Black Secondary Students. Research in the Schools, 7, 19-26. 